\title{
Presentación del dossier
}

El dossier que aquí presentamos ${ }^{1}$ reúne trabajos sobre el movimiento judeo-progresista en Argentina, Uruguay, Brasil y Chile durante el siglo XX. Desde los años 30, en tiempos de Frente Popular y lucha antifascista, varias organizaciones israelitas laicas de habla idish adhirieron al Yiddisher Kultur Farband (YKUF) fundado en Paris en septiembre de 1937. Y más tarde al Idisher Cultur Farband (ICUF) fundado en Buenos Aires en abril de 1941. Orientadas por la política del Partido Comunista, las entidades adheridas a esta Federación se expandieron notablemente durante las décadas del 40 y el 50. En distintos barrios y localidades con presencia de inmigración judía de izquierda se desarrollaron bibliotecas, centros culturales, teatros, escuelas, cooperativas, clubes juveniles, círculos femeninos y actividad editorial y de prensa. En un primer momento, los inmigrantes buscaron replicar las experiencias politicas y culturales del viejo hogar europeo; posteriormente, con la aparición de una generación de hijos nativos, y al calor de las transformaciones de los años 60, la red icufista ${ }^{2}$ iría adoptando el castellano o el portugués para incluir a la juventud e integrarse plenamente a la vida nacional.

Los artículos que integran este dossier dan cuenta de una identidad muy difundida, pero escasamente explicada desde su complejidad étnico-política. Se trata de instituciones que propagaron un judaísmo laico, no sionista y en línea politica con el Partido Comunista. Esta red ha comenzado a recibir atención por parte de los investigadores a partir de

\footnotetext{
1. Los autores agradecemos el apoyo permanente y el espacio editorial brindado por la revista Archivos y el CEHTI para la publicación de este dossier.

2.Si bien el judeo-progresismo incluyó propuestas institucionales que excedieron la adhesión formal al ICUF, podemos decir que, en Sudamérica, la red "icufista" y la "judeo-progresista" se superponen y por su similitud ideológica las consideramos equivalentes.
}

(Archivos, año VIII, $\mathrm{n}^{\circ}$ 15, septiembre de 2019, pp. 7-15) 
la caída de la URSS y cuando, con el paso del tiempo, "ser comunista" o hablar francamente de ello dejó de implicar poner en riesgo la vida, propia o ajena. Es decir, un renovado interés por la recuperación de archivos y la distancia temporal con el fenómeno soviético han permitido una fructífera recolección de fuentes documentales y testimoniales que dieron origen a nuevos trabajos (Visacovsky, 2015: 24). Sin embargo, el judeo-progresismo no se ha constituido todavía como un campo autónomo de estudios, y en ese sentido se direcciona nuestra propuesta. La red institucional icufista o la federación ICUF, aún aparecen colateralmente en otros estudios de inmigración judía, de comunismo y de educación o cultura, debido a sus experiencias vanguardistas en esas áreas.

Entonces, el icufismo como objeto de estudio ha producido distintos abordajes disciplinares y temáticos. Aquello nos ha inclinado a la necesidad de reunir esas dimensiones divorciadas para comprenderlo desde una mirada integradora. En este camino, observamos que no sólo su carácter multifacético ameritaba una contemplación desde distintos ángulos, sino que los vínculos entre grupos, asociaciones y países tornaban imprescindible reconstruir las redes trasnacionales. Así también, quienes estamos abocados a la reconstrucción de esta identidad, dónde se cruzan elementos étnicos e ideológicos que no pueden ser escindidos, nos encontramos frente a grandes desafios. En primer lugar, la dificultad que implica abordar ese gran universo cultural y político construido, al menos hasta los años 60, en idioma ídish. En segundo lugar, la indispensable tarea de priorizar abordajes nacionales para establecer semejanzas y diferencias entre países. Y, por último, desafiar la tendencia predominante que se ha ocupado únicamente de los conflictos emanados entre sionismo y comunismo, y no de lo que la conjunción judeo-progresista significó en la vida real de las personas. En ese sentido, nuestro aporte aquí consiste no sólo en explicar los grandes discursos que modelaron esa identidad, sino en develar las actuaciones de redes de individuos concretos, politizados, contradictorios, con historias familiares, emociones, y conmovidos por un mundo cambiante y proyectos utópicos (Elias, 2006). Los trabajos que siguen a continuación se inclinan en ese sentido y no sólo asumen los tres desafios recién señalados, sino que nos incitan a pensar acerca del valor incalculable de la perspectiva comparada para formular nuevas hipótesis de investigación.

Para contextualizar estas experiencias, es preciso mencionar antes ciertos hitos que resultaron clave en la conformación de esta identidad. Los Congresos de Cultura Ídish que fundaron el ICUF se suscitaron en una coyuntura marcada por la lucha antifascista, pero a la vez se plantearon como continuaciones de otras experiencias previas. Principalmente nos referimos al Congreso de Czernowitz (Ucrania), celebrado entre el 
30 de agosto y el 4 de de septiembre de 1908, liderado por reconocidos escritores socialistas como Iztkoj Leibush Peretz, Sholem Asch y Jaim Zhitlovsky, entre otros. Frente a la "erudición" de las elites judias que utilizaban el hebreo, el alemán o el ruso y menospreciaban el idioma de las grandes masas del este europeo, en Czernowitz se declaró al ídish como idioma nacional del pueblo judío. Aquello significaba el triunfo político de una vanguardia intelectual secularizada que, influenciada por la Ilustración, se había propuesto construir "cultura" en el idioma cotidiano de los cinco millones de judios que vivian confinados en la Zona de Residencia del imperio zarista. La difusión literaria del ídish constituía la clave para sacar a las masas del analfabetismo y, además, involucrarlas con causas socialistas y emancipatorias. Posteriormente, hacia la década del 30, expresiones similares, reivindicatorias de la cultura popular idishista, surgieron como bandera de lucha frente al dramático avance del fascismo y el antisemitismo. Así, se realizaron encuentros de escritores judíos en 1934, en Moscú; en abril de 1935, en Nueva York; y en agosto de 1935, en Vilna. Paralelamente, dos acontecimientos de la izquierda internacionalista convergieron en esa coyuntura histórica. Por una parte, el "Primer Congreso de Escritores en Defensa de la Cultura", realizado entre el 21 y el 25 de junio de 1935 en París. ${ }^{3}$ Por otra, el VII y último congreso de la Komintern, realizado en Moscú en agosto de 1935, dónde se llamó a constituir Frentes Populares. De acuerdo a esto último, las secciones idiomáticas de habla ídish de la Tercera Internacional buscaron construir alianzas con los socialistas del Bund, el sionismo socialista de Linke Poale Sion y la "burguesia judia progresista" en general. En esta nueva etapa de colaboración de clases, los comunistas de habla ídish se integraron a un movimiento antifascista más amplio que les permitió crecer notablemente, pero cuyo precio fue soslayar las tensiones preexistentes, derivadas de un mundo de "explotadores y explotados".

Cabe destacar también que, en América del Norte, la organización

3. Alli participaron 230 delegados de 38 países quienes fundaron la Federación Internacional de Escritores en Defensa de la Cultura. La intelligentsia antifascista francesa, encabezada por Romain Rolland, André Gide, André Malraux y Henri Barbusse entre otros, recibieron a figuras como Sinclair Lewis, Upton Sinclair, Heinrich y Thomas Mann, Bertolt Brecht, Bernard Shaw, Selma Lagerlof, Ilya Ehrenburg y Máximo Gorki. Entre los latinoamericanos, Raúl González Tuñón y Pablo Neruda. Existe una versión que indica que fue Ilya Ehrenburg y otros escritores judíos participantes en ese congreso quienes, al terminar, resolvieron que era imperioso hacer un evento similar, pero con escritores exclusivamente de habla ídish, cuya identificación con la URSS estaba en su cúspide en tanto se había establecido como el idioma oficial de la Región Autónoma de Birobidyán. Además, existía una preocupación por la "asimilación" idiomática de los inmigrantes y sus hijos en América y países del occidente europeo (Gliksberg, 2008: 6). 
International Workers Order, creada en 1930 e integrada por diversos grupos étnicos, tenía su fortaleza en los miembros de la Jewish People Fraternal Order (JPFO) en Estados Unidos y la United Jewish People's Order (UJPO) en Canadá. Sus dirigentes e intelectuales, radicados en Nueva York y Toronto, proyectaron y financiaron junto con los europeos la fundación del Yiddisher Kultur Farband en 1937. Entonces, mientras en los países americanos los gobiernos combatian el "internacionalismo comunista", en la Francia liderada por el socialista judio León Blum, París fue el epicentro del idishismo de izquierda. En definitiva, el surgimiento del ICUF encuentra sus raíces en una convergencia de ideas y luchas tanto étnicas como políticas.

A mediados de 1936, el inicio de la Guerra Civil Española movilizó acciones solidarias entre grupos judios de todo el mundo, que entendieron la defensa de la causa republicana como un primer acto de resistencia contra el antisemitismo. ${ }^{4}$ A pesar de los numerosos conflictos entre socialistas, anarquistas, sionistas y comunistas, estos últimos lograron predominar con su llamado a la unidad e invitaron al Primer Congreso de la Cultura Judía. Y esa convocatoria, no sólo fue exitosa porque los comunistas iban siendo cada vez más, sino porque en su propuesta recogian las tradiciones decimonónicas del Idishkait europeo, porque la URSS estaba jugando un rol decisivo en el apoyo a los republicanos y porque las Leyes de Nüremberg, de septiembre de 1935, ya no admitían seguir autofragmentándose.

Entonces, entre el 17 y el 21 de septiembre de 1937 en París, 104 delegados provenientes de 23 naciones ${ }^{5}$ en representación de 677 orga-

4. A partir del 17 de julio 1936, al estallar la Guerra Civil Española y con el llamado a conformar Brigadas Internacionales que la Komintern realizaria en septiembre de ese año, las acciones solidarias en defensa de la República potenciaron la movilización frentepopulista judía. El fascismo había sido definido por el VI Congreso de la Komintern (julio de 1928), como una demagogia social que, entre su múltiples formas de captar a las masas y los intelectuales para explotar su descontento, inyectaba "antisemitismo" en la sociedad (Crespo, 2010: 41). Se calcula que, hasta abril de 1939, cerca de 35.000 voluntarios de más de 50 países participaron de las Brigadas Internacionales y cerca de 4.000 eran de origen judío. Además, aquellos judíos socialistas que venian de Polonia formaron la compañia Naftali Botwin, creada como unidad judía en el batallón Palafox XIII de la Brigada Dombrowsky. La sobrerrepresentación de voluntarios judios en España descansa principalmente en la tesis de que los judios no sólo fueron a combatir a Franco, sino a sus aliados Hitler y Mussolini, y que fue ese el primer gran acto de resistencia judia contra el fascismo. Esta interpretación contribuye a desmitificar una supuesta "pasividad judia" frente al genocidio nazi (Zaagsma, 2017: 2).

5.Los países eran Alemania, Argentina, Australia, Austria, Bélgica, Brasil, Canadá, Checoslovaquia, Cuba, Dinamarca, Estados Unidos, Francia, Gran Bretaña, Holanda, Italia, Letonia, Lituania, México, Palestina, Polonia, Rumania, Sudáfrica, Suiza y Uruguay. La 
nizaciones se reunieron en la Sala Wagram y en el Palace de la Mutualité. La comisión anfitriona estuvo encabezada por el escritor francés Haim Slovès, y los discursos generales, a cargo de Moishe Olguin, Joseph Opatoshu, Alexander Mukdoni, H. Leivik, Rubin Saltzman y Kalman Marmor, entre otros. Se trataba de reconocidos intelectuales, quienes ofrecieron diagnósticos de los acuciantes problemas para el idioma y la cultura ídish. ${ }^{6}$ Asimismo, los delegados expusieron la situación específica en sus países. Por Brasil disertó Menajem Kopelman, y por Argentina y Uruguay, Pinie Katz. ${ }^{7}$ Durante los cuatro dias del Congreso, trabajaron en comisiones de literatura, teatro, arte, escuelas, universidad y ciencias, organización y estructura del YKUF y redacción de un "Manifiesto". Ese documento final propuso combatir el fascismo y el antisemitismo generando instituciones educativas, culturales y un intenso trabajo de prensa y editorial en ídish, mientras cada comisión elaboró un listado de tareas comunes que los delegados impulsarian en los países representados. En cuanto a su estructura, la Federación determinó que la Dirección Central del YKUF estuviera radicada en París con dos subdirecciones en Nueva York y Varsovia. Así también se resolvió crear un fondo colectivo, solicitando a cada sección nacional enviar un porcentaje de sus recaudaciones, a cambio de libros y revistas culturales. Sin embargo, debido a la tragedia que asolaba a Europa, aquella diagramación internacionalista quedó desmembrada. Pero volvamos la mirada a lo que sucedió, a partir de entonces, en Sudamérica.

En Argentina, país con mayor inmigración judía de la región, el delegado Katz y un pequeño grupo trabajaron incansablemente para cumplir cada punto acordado en el Manifiesto. Desde noviembre de 1937, y no exentos de conflictos ideológicos y financieros, el comité ejecutivo de la sección nacional del YKUF (aún integrado por socialistas, sionistas y comunistas) organizó encuentros con instituciones de las provincias y países limitrofes para brindar conferencias culturales e incentivar la formación de una red judeo-progresista. Sus ideales de izquierda y su mundo idishista los unían, pero las disputas se generaban entre quienes

delegación rusa fue la gran ausente. La norteamericana que había sido liderada por el escritor Jaim Zhitlovsky, quien no pudo viajar por estar enfermo, era la más potente y numerosa con 11 delegados representando a 442 organizaciones (Kornecki, 2005).

6. Primer Congreso Universal de la Cultura Judia; París, 17 a 21 de septiembre de 1937. Edición original: Ershter Alveltlekhjer Idisher Kultur Kongres, París, Comité Central del YKUF, 1937. Traducido del ídish por Kornecki (2005).

7. Pinie Katz habia llevado un informe producido por el "Comité Preparatorio" que había iniciado sus tareas a mediados de 1936, cuando llegó la carta de invitación. Ese comité estuvo integrado por S. Glazerman, J. Botoshansky, L. Zhinitzky, L. Groisman, J. Goldszer, S. Drúcaroff, S. Wasserman, I. Kovenski, W. Kuper, M. Lev y A. Moscovich (Gliksberg, 2008: 7). 
querían crear una federación argentina similar, pero políticamente independiente del YKUF, y quienes, por el contrario, acataban los acuerdos internacionalistas direccionados por la linea comunista. Estos últimos lideraron finalmente y, en abril de 1940, editaron el primer número de la Revista ICUF. Con una abnegada actitud militante, los icufistas alentaron proyectos para construir teatros, escuelas, una editorial propia, y replicaron el Congreso de la Cultura Judía en Buenos Aires. ${ }^{8}$ El 11 de abril de 1941, con 57 instituciones representando a 8.900 asociados de Argentina, Uruguay, Brasil y Chile, se creó el ICUF local y se declaró a Pinie Katz su presidente honorario.

Como veremos en este dossier, las instituciones adheridas constituyen el corazón vital de la historia judeo-progresista y tuvieron diferentes destinos y períodos de duración, según las características de cada localidad. En cambio, las federaciones sólo tuvieron efecto en coyunturas muy favorables. En Buenos Aires, por ejemplo, el ICUF sigue vigente, aunque perdió la fortaleza que supo tener en los años 50 . En Montevideo, la organización ICUF actuó hasta 1968, cuando la fusión de varias instituciones en una sola hizo que su existencia perdiera sentido. En Brasil, el ICUF se creó en 1950 en un congreso realizado en Río de Janeiro con 75 delegados y se disolvió durante el régimen dictatorial, en 1970. En Chile, tratándose sólo de una entidad, no tuvo lugar esta conformación federativa. No obstante, lo que queremos analizar aquí es cómo los ideales planteados por el icufismo encarnaron en estas colectividades idishistas del sur. Para eso elegimos un orden diacrónico en la presentación de los trabajos. El primero, de nuestra autoria, se ocupa de los origenes y el devenir del icufismo en el Río de la Plata entre la Primera Guerra Mundial y el inicio de la Guerra Fría, planteando que las experiencias institucionales reflejan la construcción de una identidad modelada en un campo de tensiones entre la pertenencia étnica, los lineamientos del Partido Comunista y la aspiración colectiva de integración nacional, argentina y uruguaya. A continuación, Valeria Navarro-Rosenblatt recrea la historia de la Sociedad Progresista Israelita (1938), luego devenida Centro Cultural Scholem Aleijem (1951) en Santiago de Chile, e indaga en los problemas vinculados a la memoria histórica que impidieron conocer más sobre la existencia de esas entidades. La ausencia, lejos de ser casual, responde a una batalla ideológica dónde el sector sionista triunfó y, deliberadamente, marginó a los progresistas de la historia judía chilena. No obstante, la autora adjudica también este "olvido" a la falta de transmisión por parte de

8. Actas del Comité Preparatorio de la Federación ICUF en Argentina (1937-1940). Traducido del ídish por Isaac Rapaport, Centro Documental y Biblioteca (CeDob) Pinie Katz, 2019. 
los propios activistas. Finalmente, el trabajo de Airan Milititsky Aguiar se ocupa de mostrar una faceta central de la historia icufista, a través del Club de Cultura de Porto Alegre de Río Grande do Sul. El autor nos perfila el trayecto de una entidad fundada por los inmigrantes judios comunistas en 1950 que, acorde a sus principios universalistas, abrió sus puertas a la izquierda brasileña, para convertirse en su refugio durante la dictadura de 1964 y volverse emblema cultural de la ciudad.

Los tres artículos desarrollan procesos con rasgos similares, que podrian ser intercambiables, pero, al mismo tiempo, revelan particularidades autóctonas que brindan interesantes perspectivas analíticas. Sólo para ofrecer algunos ejemplos entre los múltiples posibles, podemos notar cómo, después de la Revolución Rusa de 1917, los "judios-bolcheviques", en distintos grados, fueron acusados de propagar el "peligro rojo" en los cuatro países estudiados. Sin embargo, en Argentina, donde la presencia idishista en el movimiento obrero era más intensa, fueron mayores las movilizaciones, y también las consecuencias represivas que sufrieron. En los cuatro casos, los años 50, signados además por el bienestar económico y el ascenso social de los sectores medios, marcaron la consagración del desarrollo institucional y la definitiva ruptura con el sionismo. El movimiento pudo generar actividades para niños y jóvenes en los sitios más poblados, y se concentró en acciones culturales de adultos donde el entorno era más limitado. En todos los países, las entidades funcionaron como espacios de contención para militantes y simpatizantes comunistas. Mientras en Brasil actuaron como semillero de cuadros dirigentes que se incorporaron a la política nacional; en Argentina el proceso fue inverso, y más bien resultaron receptoras de militancia judeo-comunista. Esto es menos claro en Chile y Uruguay, dónde la izquierda idishista fue más reducida. La condición de estas entidades como "semilleros culturales" o "vanguardias pedagógicas" es un común denominador en las cuatro naciones.

En los años 60, la acelerada transformación del icufismo, a raíz de la aparición de la juventud, el pasaje al castellano o al portugués, la pérdida de activistas y el surgimiento de nuevos espacios de participación, afectaron a todo el conjunto. Naturalmente, si bien existen factores coyunturales que explican el cierre, la fusión o la continuidad de las instituciones, aquello no puede comprenderse sólo desde circunstancias nacionales o internacionales, por lo cual cada una amerita su análisis específico. No obstante, y por último, los tiempos de las dictaduras cívico-militares con improntas anticomunistas y antisemitas (Brasil desde 1964, Argentina en 1966 y 1976, Uruguay y Chile desde 1973) fueron devastadoras para toda la red judeo-progresista.

En nuestros países, y más allá de las directivas de los Partidos Comunistas, la intensa ligazón emocional del icufismo con el mundo soviético 
fue un elemento fundamental en la conformación de esa identidad. Si la Unión Soviética había salvado a los judíos de las "garras del nazismo", ser idishista, laico y comunista era casi una condición natural, al menos hasta mediados de los años 50. Sin embargo, a partir de la creación del Estado de Israel en 1948 y con el paulatino crecimiento del sionismo y la difusión del hebreo como idioma oficial de la nueva nación, el concepto de "judaísmo" entró en crisis. Tanto para la opinión pública como para varios de sus protagonistas, "lo judío" comenzó a asociarse a "lo sionista" o "lo religioso". Por ese motivo, cuando en los años 70 el ídish y los idishistas empezaron a desaparecer, las nuevas generaciones se enfrentaron con un conflicto todavía no resuelto: ¿cómo se expresa la identidad judia sin idioma, sin religión y sin sionismo? Esa y otras preguntas aún navegan en los debates del movimiento judeo-progresista, que trata de explicarse y explicar cómo se entiende esa identidad en el siglo XXI. El problema, claro está, excede nuestro análisis, pero siempre es útil recordar al genial Isaac Deutscher cuando reflexionaba:

Si no es la raza, ¿qué es entonces lo que hace judío a alguien?; ¿la religión?, soy ateo; ¿el nacionalismo judío?; soy internacionalista. Por lo tanto, no soy judío en ningún sentido. $\mathrm{Y}$, sin embargo, soy judío a causa de mi solidaridad incondicional con los perseguidos y exterminados. Soy judío porque siento la tragedia judia como mi propia tragedia; porque siento el pulso de la historia judía; porque me gustaría hacer todo lo posible por la seguridad y autorrespeto de los judíos. (1969: 51)

Como todo movimiento, el judeo-progresismo ha sido dinámico y ha cambiado de acuerdo a las coyunturas nacionales e internacionales a lo largo del siglo XX. En este dossier nos proponemos reconstruirlo teniendo en consideración la mirada de los propios sujetos y formulando un análisis que permita alejarnos de formas estereotipadas y, a menudo, estigmatizadas. Por eso, tanto el estudio exhaustivo de casos institucionales, con sus protagonistas y sus conflictos, como el abordaje de dimensiones culturales y educativas, además de las partidarias, nos han convencido de la condición indisociable de elementos étnicos y políticos para dar cuenta de esa identidad. Finalmente, el "futuro socialista" como motor ideológico de toda aquella experiencia no pudo haber sido tal sin el componente asociacionista, solidario y utópico que caracterizó a esos colectivos obreros y revolucionarios.

Nerina Visacovsky 


\section{Bibliografía}

Crespo, Horacio (2010), "La Internacional Comunista", en Alexandra Pita González (coord.), Intelectuales y antiimperialismo: entre la teoría y la práctica, México: Universidad de Colima, pp. 15-47.

Deutscher, Isaac (1969), Los judios no judios, Buenos Aires: Kikiyon.

Elias, Norbert (2006), Sociología fundamental, Barcelona: Gedisa.

Gliksberg, Isaac (2008), "Um aporte valioso", en $A S A, \mathrm{n}^{\circ} 114$, septiembreoctubre, Río de Janeiro, pp. 6-7.

Kornecki, Vladimir (2005), Notas para la historia de ACIZ, Archivo ACIZ, Montevideo, traducida del ídish.

Rapaport, Isaac (2019), Actas del Comité Preparatorio de la Federación ICUF en Argentina (1937-1940), Centro Documental y Biblioteca (CeDob) Pinie Katz, traducida del idish.

Visacovsky, Nerina (2015), Argentinos, judios y camaradas. Tras la utopia socialista, Buenos Aires: Biblos.

Zaagsma, Gerben (2017), Jewish volunteers. The international brigades and the Spanish Civil War, London: Bloomsbury Academic. 